\title{
Motion Capture Systems Using Optimal Signal Processing Algorithm: A State-of-the-art Literature
}

\author{
Md Masud Rana, Nazia Halim* \\ Department of Electronics and Communication Engineering \\ Khulna University of Engineering \& Technology, Bangladesh
}

Copyright $\bigcirc 2018$ by authors, all rights reserved. Authors agree that this article remains permanently open access under the terms of the Creative Commons Attribution License 4.0 International License

\begin{abstract}
Motion capture system is a promising research area but the availability of the state-of-the-art literature review on this topic is limited. This research provides a comprehensive literature review for motion capture systems with Kalman filtering algorithms. The summarized state-of-the-art literature review of motion capturing system is being analyzed considering the advantages and the disadvantages of motion capture systems using Kalman filtering algorithm. Afterwards, the human body incorporating noises is represented by system of equations where the system states are unknown. The Kalman filter is adopted to estimate the human body orientations. Simulation results show that the proposed algorithm can be used to track human body orientation accurately.
\end{abstract}

Keywords Human Body Orientation, Sensors, Kalman Filter, Motion Capture Systems

\section{Introduction}

In today's world, motion capture has proven to be an extremely useful technique for animating human and human like characters. Motion capture is the process of sampling the position and location information of a subject over time. The subject usually can be a person, an animal or a machine. Basically, the Kalman filter is an optimal estimation algorithm that can track human body segment, temperature, noise system or many kinds of systems. Motion capture system is a promising research area but the availability of the state-of-the-art literature review on this topic is limited. Being driven by this motivation, this paper provides a comprehensive literature review of motion capture using Kalman filter (KF). The main contributions are summarized as follows:

- A comprehensive state-of-the-art motion captures system is being analyzed with advantages and disadvantages of different approaches.
- The human body is represented by system of equations corrupted by noises where the system states are unknown. The Kalman filter is adopted to estimate the human body orientations

- Simulation results show that the proposed algorithm can be used to track human body orientation accurately.

The paper is organized as follows. A comprehensive literature review of motion capture systems using Kalman filter has been discussed in Section 2. Section 3 elaborates signal processing algorithm. Simulation results are described in Section 4. It has been ended up with a conclusion in Section 5.

\section{Literature Review}

This research provides a comprehensive literature review for motion capture (MoCap) systems using KF algorithm. The KF can estimate the system state when it cannot be measure directly [1-4]. Tables 1-2 show the state-of-the-art literature review for MoCap systems. The KF can play important role in marine integrated navigation system and radar tracking system because it helps to decrease error [5-8]. A very useful technique of wearable sensors can be used to track lower body motion capture by using a cascaded KF based sensor fusion algorithm. It has a great influence on track down joint angles of elbow and shoulder, human motion analysis: deploying sensors for gravity measurement in a body area with wearable inertial sensor. This method can accurately capture dynamic activities without drift [9-15]. For estimating human body orientation, a cascaded two steps KF can be used [16]. For estimation of the spatial orientation of body segments, sensor fusion allows to achieve more robust solutions [17]. In this case, the extended KF can be used for estimating the three-dimensional orientation of a rigid body [18, 19]. Furthermore, the multi view human pose estimation process is described in [20-22]. For determining heart rate, 
a $\mathrm{KF}$ algorithm is used in [23, 24]. It has a significant role not only in the medical science but also in weather forecasting [25]. Object tracking is another widely used term in motion capture systems [26]. IMU and position sensor can be used for fastening tool tracking based on KF scheme [27]. This recursive algorithm can enhance sensor fusion and can be applied to embedded sensor for more robust solution [28, 29]. It has been observed that KF provides accurate and suitable solution for hybrid estimation algorithm and state estimation for large-scale systems [30, 31]. Finally, it can be recognized that motion capture system using KF has great impact on industrial applications [32-37].

Table 1. (Part 1 out of 2): A comprehensive literature review of motion capture systems.

\begin{tabular}{|c|c|c|}
\hline Method & Advantage & Disadvantage \\
\hline $\begin{array}{l}\text { Object tracking based on Kalman filter } \\
{[26] .}\end{array}$ & $\begin{array}{l}\text { - } \quad \text { Can track down moving object accurately. } \\
\text { - } \quad \text { Errors are very small. }\end{array}$ & - Covariance being assumed. \\
\hline $\begin{array}{l}\text { Pperformance analysis of hybrid } \\
\text { estimation aalgorithms [30]. }\end{array}$ & $\begin{array}{l}\text { - Understanding is easy. } \\
\text { - } \quad \text { Estimation algorithm is more accurate. }\end{array}$ & $\begin{array}{l}\text { - Algorithms are scenario } \\
\text { dependent. }\end{array}$ \\
\hline $\begin{array}{l}\text { Evaluation and comparison for } \\
\text { large-scale systems [31]. }\end{array}$ & $\begin{array}{l}\text { - } \quad \text { Providing suitable solution. } \\
\text { - } \quad \text { Three types of Kalman filters. }\end{array}$ & $\begin{array}{l}\text { - The accuracy of the systems } \\
\text { will need to improve. }\end{array}$ \\
\hline $\begin{array}{l}\text { Enhanced sensor fusion based on } \\
\text { Kalman filter [28]. }\end{array}$ & $\begin{array}{l}\text { Has the ability to overcome the sensitivity } \\
\text { of the system. } \\
\text { - } \quad \text { High robustness to the uncertainties. }\end{array}$ & - The process is expensive. \\
\hline $\begin{array}{l}\text { Probabilistic now-casting of } \\
\text { object-oriented tracked convective } \\
\text { storms [25]. }\end{array}$ & $\begin{array}{l}\text { - } \quad \text { Noise parameters use physical quantities. } \\
\text { Help one to choose a reasonable } \\
\text { parameterization for the filter. }\end{array}$ & $\begin{array}{l}\text { - The system cannot stable for } \\
\text { different situations. }\end{array}$ \\
\hline $\begin{array}{l}\text { Rapid tool tracking system using IMU } \\
\text { and position sensor [27]. }\end{array}$ & $\begin{array}{l}\text { - Can estimate orientation and position } \\
\text { correctly. } \\
\text { - } \quad \text { Reduce orientation error. }\end{array}$ & $\begin{array}{l}\text { Q } \\
\text { give correct value. } \\
\text { - } \quad \text { Very lengthy process. }\end{array}$ \\
\hline $\begin{array}{l}\text { Marine integrated navigation } \\
\text { system [5]. }\end{array}$ & $\begin{array}{l}\text { Helps to decrease error on marine } \\
\text { navigation system. }\end{array}$ & $\begin{array}{l}\text { - The process and measurement } \\
\text { covariance matrices are } \\
\text { unknown. }\end{array}$ \\
\hline $\begin{array}{l}\text { Aircraft turbofan engine health } \\
\text { estimation [6]. }\end{array}$ & $\begin{array}{l}\text { - Effective method for turbofan engine } \\
\text { health estimation. }\end{array}$ & $\begin{array}{l}\text { - } \quad \text { Requires larger computational } \\
\text { effort. }\end{array}$ \\
\hline 3-D radar tracking estimation [7]. & $\begin{array}{l}\text { - Nonlinear process and measurements can } \\
\text { be solved effectively. }\end{array}$ & - Covariance being assumed. \\
\hline
\end{tabular}

Table 2. A comprehensive literature review of motion capture systems.

\begin{tabular}{|c|c|c|}
\hline Method & Advantage & Disadvantage \\
\hline $\begin{array}{l}\text { Navigation system on ultra-tightly coupled } \\
\text { SINS/GPS [8]. }\end{array}$ & $\begin{array}{l}\text { - } \quad \text { Can avoid the impact of abnormal error. } \\
\text { - } \quad \text { Tracking stability is significant. }\end{array}$ & $\begin{array}{l}\text { - Failed to detect initial } \\
\text { errors. }\end{array}$ \\
\hline $\begin{array}{l}\text { Discrete KF based sensor fusion for robust } \\
\text { accessibility interfaces [34]. }\end{array}$ & $\begin{array}{l}\text { - } \\
\text { sccessibility interfaces over small } \\
\text { - } \quad \text { More robust solution. }\end{array}$ & $\begin{array}{ll}\text { - } & \text { Less susceptible to outer } \\
\text { surface. } \\
\text { - } \quad \text { Less susceptible to its } \\
\text { environment. }\end{array}$ \\
\hline $\begin{array}{l}\text { Overview about industrial applications of KF } \\
\text { [32]. }\end{array}$ & $\begin{array}{l}\text { Summarized the research efforts made } \\
\text { over the past two decades. }\end{array}$ & $\begin{array}{l}\text { - Authors stated that KF } \\
\text { implementation in real } \\
\text { time is very complex. }\end{array}$ \\
\hline $\begin{array}{l}\text { Fault identification in a fluid catalytic } \\
\text { cracking unit [35]. }\end{array}$ & $\begin{array}{l}\text { - } \quad \text { True estimation obtains easily. } \\
\text { - } \quad \text { More accurate state values. }\end{array}$ & $\begin{array}{l}\text { - Complicated chemical } \\
\text { process. }\end{array}$ \\
\hline Optical motion captures data solving [36]. & $\begin{array}{l}\text { - The burden of hand processing is } \\
\text { reduced }\end{array}$ & $\begin{array}{l}\text { - } \\
\text { Not automatic process. } \\
\text { even if there is nothing. }\end{array}$ \\
\hline Embedded sensors being applied by KF [29]. & $\begin{array}{l}\text { - } \quad \text { Applicable for real-time systems. } \\
\text { Great capabilities to cope up with } \\
\text { complex application. }\end{array}$ & $\begin{array}{l}\text { Limited availability of } \\
\text { processing power. } \\
\text { Filter equation finds it } \\
\text { difficult to fit with low } \\
\text { power requirements. }\end{array}$ \\
\hline
\end{tabular}




\begin{tabular}{|c|c|c|}
\hline $\begin{array}{l}\text { For the improvement of orientation } \\
\text { estimation, indentifying covariance matrices } \\
{[21] .}\end{array}$ & $\begin{array}{l}\text { - } \quad \text { Can indentify covariance values. } \\
\text { - } \quad \text { Reduce the period of the process. }\end{array}$ & $\begin{array}{l}\text { - Noise covariance method } \\
\text { cannot properly estimate } \\
\text { the noises. }\end{array}$ \\
\hline $\begin{array}{l}\text { Determining orientation using inertial or } \\
\text { magnetic sensors [13]. }\end{array}$ & $\begin{array}{l}\text { - Lie derivatives can apply to test the } \\
\text { observability. }\end{array}$ & - $\quad$ Large estimation errors. \\
\hline $\begin{array}{l}\text { Miniature orientation sensor for wearable } \\
\text { human motion systems [15]. }\end{array}$ & 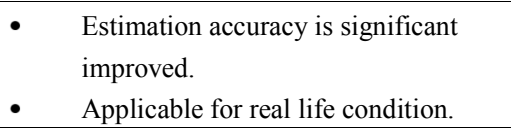 & $\begin{array}{l}\text { - } \quad \text { Failed to give explanation } \\
\text { about noise affected } \\
\text { sensors. }\end{array}$ \\
\hline $\begin{array}{l}\text { Motion captures systems for lower body and } \\
\text { trajectory tracking [9]. }\end{array}$ & $\begin{array}{l}\text { Accuracy of 3D localization rise } \\
\text { remarkable. } \\
\text { - } \quad \text { Accurately track joint angles. }\end{array}$ & $\begin{array}{l}\text { - The process is more } \\
\text { complex and cannot apply } \\
\text { in real time. }\end{array}$ \\
\hline $\begin{array}{l}\text { Estimation of vertical trajectory tracking with } \\
\text { integrated inertial and pressure sensor [16]. }\end{array}$ & - Avoids unnecessary states estimation. & $\begin{array}{l}\text { This process used } \\
\text { complicated two-step } \\
\text { cascaded KF. }\end{array}$ \\
\hline
\end{tabular}

\section{KF Algorithm}

The orientation of the human body is represented by [18], [37]:

$$
s_{k+1}=\Phi s_{k}+w_{k}
$$

here, $s=[a \Delta a]^{\prime}$ is the state vector at time $\mathrm{k}$, a is the orientation of the human body, $\Delta a$ is the difference between actual and measured signal, $\Phi$ is the state transition matrix and $w_{k}$ is the white noise [33].

The measurement can be modeled as:

$$
z_{k}=H s_{k}+v_{k}
$$

here, $z_{k}$ is the actual measurement. Connection between the state vector and the measurement vector is H. $v_{k}$ is the associated measurement error [9]. $\Phi$ and $\mathrm{H}$ are given by [37]:

$$
\Phi=\left[\begin{array}{ll}
1 & -\delta t \\
0 & 1
\end{array}\right], H=\left[\begin{array}{ll}
1 & 0
\end{array}\right] .
$$

Here, $\delta t$ is the step size and $\mathrm{H}$ is the sensing matrix. Based on the process and measurement, optimal KF is adopted to estimate the system states [25]. The whole process is described in Fig. 1. It has two steps: prediction

\begin{tabular}{|c|}
\hline \begin{tabular}{ll}
\multicolumn{2}{c}{ KF algorithm: Prediction steps } \\
A priori state estimation, $\quad \hat{\mathrm{S}}_{\mathrm{i}-1}=\Phi \hat{\mathrm{S}}_{\mathrm{i}-2}$ \\
A priori error covariance, & $\mathrm{N}_{\mathrm{k}-1}=\Phi \mathrm{N}_{\mathrm{k}-2} \Phi^{\mathrm{T}}+\mathrm{Q}_{\mathrm{k}}$
\end{tabular} \\
\hline ภ \\
\hline 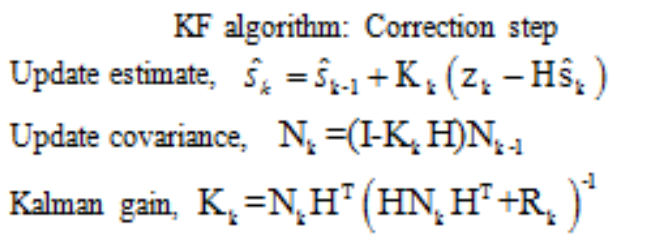 \\
\hline
\end{tabular}
and correction.

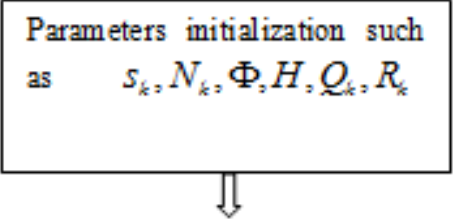

Figure.1. Flowchart of KF algorithm [37].

\section{Simulation Results and Discussions}

The process and noise covariance are assumed to be $0.005 \mathrm{I}$ and $0.05 \mathbf{I}$. Matlab is used for simulation. The simulation result is shown in Fig. 2 when step size is 0.001 sec. It is observed that the proposed algorithm can accurately track the orientation of the human body.

When the step size is $0.01 \mathrm{sec}$, the simulation is illustrated in Fig. 3. It can be seen that, the proposed algorithm can properly track the orientation of the human body. 


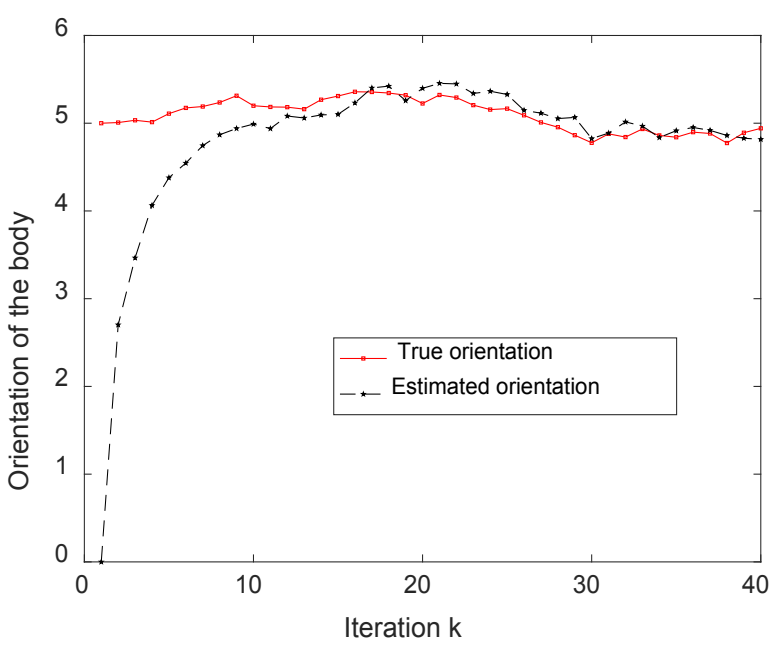

Figure 2. Orientation of the human body with step size $=0.001$.

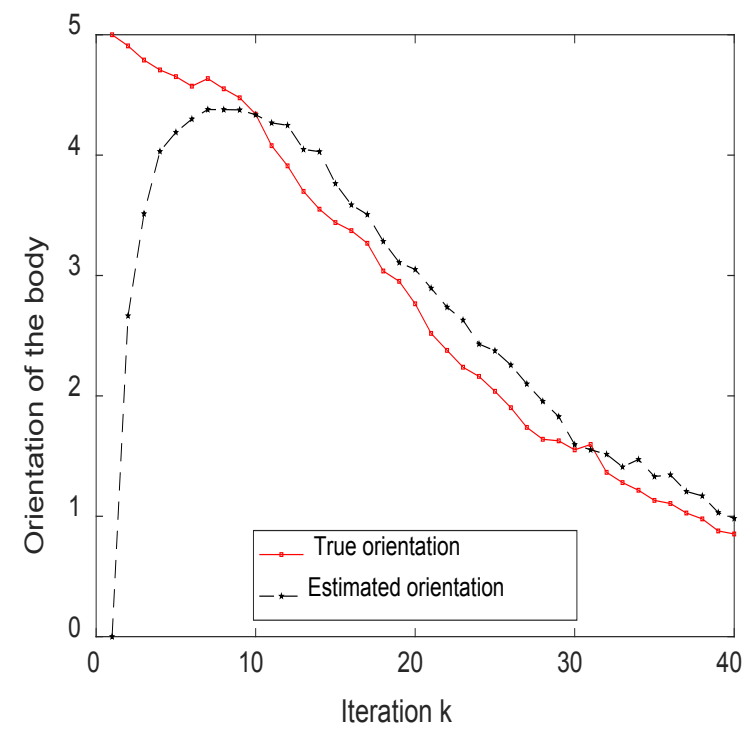

Figure 3. Orientation of the human body with step size $=0.01$.

\section{Conclusions}

A comprehensive literature review has been provided on motion capture systems using optimal signal processing algorithm. Simulation result shows that the proposed algorithm can properly track the orientation of the human body. Hopefully, this work is valuable for beginners who want to know the relative advantages and disadvantages of motion computer systems and applied methods.

\section{Acknowledgement}

Authors would like to thanks to Prof. Dr. Md. Mostafizur Rahaman, ECE, KUET.

\section{REFERENCES}

[1] S. Zihajehzadeh, D. Loh, M. Lee, R. Hoskinson, and E. J. Park, "A cascaded two-step Kalman Filter for estimation of human body segment orientation using MEMS-IMU,', in Proc. Conf. IEEE Eng. Med. Biol. Soc., Chicago, IL, USA, Aug. 2014, pp. 6270-6273.

[2] S. Khobahi, "2D object tracking using Kalman Filter," in github.com, Jan. 2017.

[3] M. Tits , J. Tilmanne, T. Dutoit, ' Robust and automatic motion-capture data recovery using soft skeleton constraints and model averaging'. PLOS ONE 13(7): e0199744, 2018.

[4] T. T. Fhuong, K. Ohishi, C. Mitsantisuk, Y. Yokokura, K. Ohnishi, R. Oboe, A. Savanovic, "Disturbance observer and Kalman Filter based motion control realization," IEE Journal on Industry Application, vol. 7, issue. 1, pp, 1-14, 2018.

[5] N. Davari, A. Gholami, M. Shabani, "Multirate adaptive Kalman filter For marine integrated navigation system,', The Journal Navigation, vol. 70, issue, 3. pp, 628-647, May. 2017.

[6] P. J. Rossi, "Kalman filtering-based probabilistic now casting of object-oriented tracked convective storms," American Meteorological Society, March 2015.

[7] P. Aditya, E. Apriliani, D. k. Arif, K. Baihaqi, "Estimation of three-dimensional radar tracking using modified extended Kalman filter," J. Phys.: Conf. Ser. Vol. 974 no. 01, pp. 2071, 2018.

[8] X. Zhao, J. Li, X. Yan, S. Ji, "Robust adaptive cubature Kalman filter and its application to ultra-tightly coupled SINS/GPS navigation system," Sensors , doi:10.3390/s18072352, July 2018.

[9] S. Zihajehzadeh, P. K. Yoon, B.-S. Kang, E. J. Park, 'UWB-Aided inertial motion capture for lower body 3-D dynamic activity and trajectory tracking," IEEE Trans. Instrum. Meas., vol. 64, no. 12, pp. 3577-3587, Dec. 2015.

[10] C.-H. Wu and Y.-C. Tseng, 'Deploying sensors for gravity measurement in a body-area inertial sensor network," IEEE Sensors J., vol. 13, no. 5, pp. 1522-1533, May 2013.

[11] M. El-Gohary and J. McNames, 'Shoulder and elbow joint angle tracking with inertial sensors,"' IEEE Trans. Biomed. Eng., vol. 59, no. 9, pp. 2635-2641, Sep. 2012.

[12] X. Chen, 'Human motion analysis with wearable inertial sensors,' Ph.D. dissertation, Univ. Tennessee, Knoxville, TN, USA, 2013

[13] A. M. Sabatini,' Kalman filter-base orientation determination using inertial/magnetic sensors: Observability Analysis and PerformanceEvaluation,'sensors.pp.9182-9206,Sept. 2011.

[14] S. Moon, Y. Park, D. K. Ko, H. Suh, “ Multiple kinetic sensors fusion for human skeleton tracking using Kalman Filter,' DOI: 10.5772/62415, February, 2016.

[15] H. Harms, O. Amft, R. Winkler, J. Schumm, M. Kusserow, G. Troester, "ETHOS: miniature orientation sensor for 
wearable human motion analysis," IEEE sensors conference, pp, 1037-1042. Nov. 2011.

[16] S. Zihajehzadeh, T. J. Lee, R. Hoskinson, and E. J. Park, “’ Integration of MEMS inertial and pressure sensors for vertical trajectory determination,"' IEEE Trans. Instrum. Meas., vol. 64, no. 3, pp. 804-814, Mar. 2015.

[17] Y. Kang, J.-F. Huang, Y.-B. Zhao, G.-P. Liu, 'Human motion analysis with wearable inertial sensors, ' IFAC Int. Conf. China, Sept. 2013.

[18] L. Tony "Tutorial: the Kalman filter 11.1 Introduction 11.2 Mean Squared Error.” 1998.

[19] A. Szczesna, P. Pruszowski, 'Model based extended quaternion Kalman filter to inertial orientation tracking of arbitrary kinematic chains," SpringerPlus. 5: 1965. https://doi.org/10.1186/s40064-016-3653-8, Dec.2016.

[20] D. Roetenberg, H. Luinge, P. Slycke, "Xsens MVN: Full 6DOF human motion tracking using miniature inertial sensors," Xsens Technologies - version, Apr 3, 2013.

[21] A. Nez, L. Fraddet, F. Marin, T. Monnet, P. Lacovture, "Idnetification of noise covariance matrices to improve orientation estimation by Kalman filter", Sensors, Oct 16. 2018.

[22] T. Nageli, S. Oberholzer, S. Pluss, J-A. Mora, O. Hilliges, "Flycon: Real-time environment-independent multi-view human post estimation with aerial vehicles", $A C M$ Transactions on Graphics, Vol. 37, No. 6, Article 182. Nov 2018.

[23] Y. Ryu, Y. Moon, J. Choi, H.C. Kim, "A Kalman filter based common algorithm approach for object detection in surgery scene to assist surgeons situation awareness in robot assisted laparoscopic surgery," Journal of Healthcare Engineering, https://doi.org/10.1155/2018/8079713, May, 2018.

[24] S. K. A. Prakash, C. S. Tuker, "Bounded Kalman filter method for motion-robust and non contact heart rate estimation," Biomedical Optics Express 873, vol. 9, no.2, Feb 1, 2018.

[25] Haykin, Simon. Kalman filtering and neural networks. Vol. 47. John Wiley \& Sons, 2004.

[26] K. Saho, "Kalman filter for moving object tracking performance analysis and system design," DOI:10.5772/intechopen.71731, Ferbruary 21, 2018.

[27] S.-H.P. Won, F. Golnaraghi, W.W. Melek, "A fastening tool tracking system using IMU and a position sensor with Kalman filers and fuzzy expert system," IEEE transactions on Industrial Electronics, vol. 56, no. 5, pp. 1782-1792, May 2009.

[28] A. Assa, F. J. Sharifi, "A Kalman-filter based framework for enhanced sensor fusion," IEEE Sensors Journal, vol.15, issue. 16, pp, 3281-3292. June 2015.

[29] A. Valade, P. Acco, P. Grabolosa, J. Fourniols, " A study about Kalman filter Applied to embedded sensors", Sensors, doi:10.3390/s17122810. Dec 5. 2017.

[30] C. E. Seah, I. Hwang, "Performance analysis of Kalman filter based hybrid estimation algorithms," IFAC proceeding volumes, vol. 41, issue. 2, pp, 13498-13503,
2008.

[31] M. Giraldo, F. Vanlencia, J. Esinosa, J. D. Lopez, "Evaluation and comparison of kalman filter based distributed state estimators for large-scale systems," IFAC proceeding volumes, vol. 46, issue. 13, pp, 188-193, 2013

[32] F. Auger, M. Hilairet, J. M. Guerrero, E. Monmasson, T. O. Kowalska, S. Katsura, "Industrial applications of Kalman-filter: A review," IEEE Transactions and Industrial Electronics, vol. 60, issue. 12, pp, 5485-5471. Dec. 2013.

[33] G. chang, M. liu, 'An adaptive fading Kalman filter based on Mahalanobis distance," Ins. Mech. Eng. Vol. 229, pp. 1114-1123, July, 2014.

[34] I. Ghersi, M. Marino, M. T. Miralles, 'Discrete Kalman filter based sensor fusion for robust accessibility interfaces," J. Phys.: Conf. Ser. Vol. 705 , 2016.

[35] G. V. Reklaitis, V. Venkatasubramanian, 'A heuristic extended kalman filter based estimator for fault identification in a fluid catalytic cracking unit," Ind. Eng. Chem. Res., vol. 42 issue, 14. pp, 3361-3371, 2003.

[36] D. Holden, " Robust solving of optical motion capture data by denoising,". ACM Trans. Graph. 38, 1, Article 165 , Mar, 2018.

[37] Olivares, Alberto, J. M. Górriz, Javier Ramírez, and Gonzalo Olivares. "Using frequency analysis to improve the precision of human body posture algorithms based on Kalman filters." Computers in Biology and Medicine 72: 229-238, 2016. 